\title{
O processo de ensino-aprendizagem do português no contexto multicultural moçambicano
}

\author{
Marcelino Horácio Velasco \\ Universidade Federal do Rio de Janeiro \\ Alexandre António Timbane \\ Academia de Ciências Policiais - Moçambique \\ Universidade Federal de Goiás- Brasil
}

\section{Introdução}

Moçambique é um país africano localizado na África Austral habitado por povos falantes de línguas do grupo bantu, língua de sinais, línguas asiáticas e outras línguas estrangeiras modernas. Apesar de ser um espaço ou ambiente multilíngue e multicultural, a recente Constituição da República (Moçambique, 2004) reconhece apenas o português como a língua oficial, língua de prestígio, da burocracia, do ensino, do funcionamento do estado e da "união". As Línguas Bantu (doravante, LB) moçambicanas são distribuídas de forma desigual ao longo do país, até porque cada língua identifica uma etnia ou uma povoação. Cada etnia ou povoação possui uma cultura própria, com hábitos culturais próprios que caracterizam o modo de ser e de estar na sociedade.

No contexto moçambicano, não se pode deixar de observar que a qualidade do ensino deixa a desejar, pois procura satisfazer as estatísticas dos financiadores internacionais como o Banco Mundial e o Fundo Mundial Internacional, deixando cidadãos em estado de analfabetismo funcional. Levantou-se esta constatação porque as políticas educacionais moçambicanas se preocupam com o número de aprovados em cada ano e em cada série (classe), deixando de lado a qualidade que é mais importante a nosso ver. Os professores se sentem "pressionados" em fornecer estatísticas positivas no fim do ano sem que haja uma observação profunda da qualidade de ensino. Há pouco investimento nas infraestruturas havendo até agora turmas que funcionam ao relento (as famosas 'salas-sombra', 'salas-machimbombo', 'salas-improviso'). 
Além disso, a educação moderna não toma em conta as diferentes manifestações culturais dos diferentes povos, principalmente nas áreas urbanas e suburbanas. Muitas colocações no espaço escolar tendem a criticar e a modificar as regras tradicionais daquele povo adotando a cultura europeia. Só para ilustrar: por que a escola proíbe o uso da língua local? Por que a escola entende que andar descalço é errado? Por que a escola desencoraja os ritos de iniciação? Por que a escola e a sociedade atual não valorizam mais (e até desencorajam) o dote? Se a cultura é a identidade, questiona-se que identidade essas crianças terão? Por que a escola prioriza a literatura e menospreza a oratura? Por que a escola não promove o ensino de (história, biologia, matemática, etc.) através de provérbios?

Estas e outras questões serão discutidas ao longo deste capítulo, mas sem fugir ao fato de que os moçambicanos estão sempre copiando 'modelos de ensino estrangeiro' que, em muitos momentos, não satisfazem a realidade prática local do aluno. Assim, como se pode falar que Moçambique é lusófono, se possui apenas $10,7 \%$ (INE, 2009) da população que fala português como língua materna? Entendemos que Moçambique é 'lusófono' sob o ponto de vista político, mas bantófono sob ponto de vista prático e real. Os sistemas de ensino moçambicano utilizados desde período pós-colonial são na maioria importados e aplicados em contexto moçambicano sem que haja uma reflexão sobre os aspectos socioculturais daquele espaço geográfico. Talvez seja esta a razão pela qual as reprovações em massa são uma realidade naquele contexto.

A escola prepara/forma cidadãos para inseri-los na sociedade e não desvinculá-los da sua cultura e do seu povo. Esse é o nosso entendimento. Que o indivíduo formado pela escola seja porta-voz da sua comunidade na luta pela igualdade, na conquista dos direitos que, muitas vezes, são violados pela política vigente, mas sobretudo guerreiro no desenvolvimento endógeno (Ki-Zerbo, 2006) da sua comunidade. Após o término dos estudos, este aluno não vai viver na Europa. Viverá na sua comunidade e enfrentará os hábitos e costumes que lhes foram proibidos aprender pela escola. A nosso ver, a escola deveria ser o espaço da consolidação das culturas para que elas possam ganhar força e se fazerem sentir pelo mundo afora.

Nas áreas rurais, pais e encarregados pela educação das crianças ainda mandam/enviam seus filhos para os ritos de iniciação durante as férias escolares, porque perceberam que a escola não consegue dar conta da educação necessária, básica e fundamental para a integração do futuro responsável pela continuação da geração naquela comunidade, que é a criança. A educação formal moçambicana ainda está longe de satisfazer a realidade das comunidades e isso não anima os pais, atitude que resulta em altos índices de abandono escolar, tal como se verificou em 2014, em que a taxa atingiu 69,4\% (Malik, 2014) principalmente nas zonas rurais. 
Toda a educação formal é feita em português pelo fato de ser considerada língua de prestígio, oficial e amparada pelos artigos $9^{\circ}$ e $10^{\circ}$ da Constituição da República de Moçambique (Moçambique, 2004), instrumento que, apesar de (re) definir o mais recente quadro jurídico e normativo-legal do país, não dá relevância às diversas LB moçambicanas faladas pela maioria da população. Isso nos parece uma violação dos Direitos Linguísticos ${ }^{1}$, pois não existe uma língua inferior que a outra, nem existe uma língua pobre e incapaz. Todas as línguas respondem às necessidades comunicativas dos seus falantes.

Neste capítulo, portanto, pretende-se discutir aspectos relativos ao ensino fundamental em Moçambique, no que se refere às experiências de práticas linguísticas no espaço escolar e as possíveis causas do fracasso escolar entre alunos provenientes de famílias pertencentes às classes multiculturais. Traremos ao debate as questões inerentes à cultura e sua relação com o ensino formal nesse contexto. É válido salientar que a maior parte da população localiza-se nas zonas rurais, onde ainda preservam-se traços da sua cultura. Assim, dada à complexidade que caracteriza a identidade linguística, étnica e cultural dos moçambicanos, novos desafios se impõem ao ensino fundamental, sobretudo no que se refere ao processo de formação do professor que possa receber e atuar diante de alunos provenientes de uma cultura diversificada. Isso inclui a questão da educação bilíngue que vem sendo implementada em Moçambique desde que se iniciou o Projeto de Educação Bilíngue anos após o $3^{\circ}$ seminário de Padronização da Ortografia das Línguas moçambicanas em 2008.

Nesse sentido, as práticas docentes e os níveis de uso das línguas são fatores decisivos para o sucesso ou fracasso escolar dos alunos do ensino fundamental. Recomenda-se que o Estado moçambicano possa efetivamente tornar o ensino bilíngue uma realidade fiável na formação das crianças tanto nas zonas rurais quanto nas zonas urbanas. Defendemos esta perspectiva pelas seguintes razões: (a) linguístico-pedagógicas: pelo fato de existir uma diversidade linguística no país; (b) culturais e de identidade: a língua é a riqueza cultural e de identidade de uma comunidade ou grupo étnico; (c) direitos humanos e linguísticos: significa que todo indivíduo tem o direito de aprender a língua do seu povo (Unesco, 1996, Declaração Universal dos Direitos Linguísticos).

Nos Países Africanos de Língua Oficial Portuguesa (PALOP), nomeadamente Moçambique, Angola, Guiné-Bissau, Cabo Verde e São Tomé e Príncipe, e

1. É a garantia expressa pela lei fundamental de qualquer país democrático, comprometendo-se a respeitar as diferenças linguísticas e culturais dos seus cidadãos, culminando com a proteção e respeito às línguas ditas minoritárias. Ex: o direito regulado pela Constituição Federal Brasileira no seu artigo 210, § $2^{\circ}$, da CF/88 que assegura que os cidadãos indígenas têm direito à utilização de suas línguas maternas no processo de aprendizagem. 
recentemente na Guiné Equatorial, a LP é oficial por opção política feita pelos regimes pós-independentistas e não por falta de opções linguísticas. A escolha da língua do colonizador para fins oficiais se verificou em quase todos os países africanos. Não se pode deixar de elogiar a coragem política da África do Sul, ao oficializar onze línguas das quais dez são africanas. O crioulo afrikaans é também uma língua natural de origem africana, por isso, não há dúvidas sobre a sua importância para a população daquele país. Desde a nova Constituição da República Sul Africana, de 1997, nunca se observou guerras naquele país devido às línguas oficializadas. É uma prova viva do sucesso e da importância da tomada de políticas linguísticas acertadas para a cultura.

A história da colonização em Moçambique, bem como as relações com outros povos e culturas, criou para a LP uma diversidade de situações de contato linguístico em diferentes contextos de aprendizagem. Se a cultura é a base de integração das crianças na sociedade, como tem sido tratada no seio escolar? Avança-se na hipótese de que a escola não se vê com o dever de transmitir a cultura e que essa tarefa é incumbida à família; os professores não têm uma formação específica para lidar com essa questão; os manuais escolares não apresentam conteúdos que discutem valores culturais para que sejam discutidos em sala de aula.

Essa pesquisa resulta da nossa inquietação pela falta de respeito e pelo comportamento desviado de muitos alunos no espaço escolar tanto no Brasil quanto em Moçambique. Atualmente, é comum ouvir-se: "as crianças de hoje não têm respeito com professores, funcionários da escola e com os colegas!” A nossa experiência como professores em vários níveis de ensino mostrou a necessidade de a escola ser a extensão da família, pois existem regras comuns aceites na convivência humana. Analisando mais profundamente, existem regras de convivência na família, na comunidade e na nação. Nas culturas tradicionais africanas do grupo bantu (como é o caso de Moçambique), toda a sociedade tem a obrigação de educar, exigir e policiar qualquer criança ao cumprimento das regras morais da comunidade. Nesse sentido, a criança não nasce apenas para família, mas sim para a comunidade, portanto, é tarefa da sociedade policiar e educar.

Com esse intento, utilizamos uma pesquisa bibliográfica que traz ao debate posições e ideias de pedagogos, para além da nossa experiência como professores há mais de vinte anos. O capítulo inicia-se dissertando sobre a situação da educação em Moçambique e apontando para o planejamento linguístico que influencia na formação do aluno. Mais adiante, levantam-se questões de bilinguismo e da sua relação com a realidade sociolinguística moçambicana. O bilinguismo em Moçambique é o normal, principalmente nas zonas suburbanas e rurais onde reside a maioria da população. Discute ainda as práticas docentes e os desafios de 
uma educação bilíngue num espaço onde há falta de materiais e políticas públicas que protejam as línguas locais. O capítulo termina apresentando a tripartida relação entre língua, cultura e ensino em contexto multicultural, como é o caso de Moçambique.

\section{Algumas questões sobre o ensino em Moçambique}

Segundo Timbane (2009), no seu estudo sobre "A problemática do ensino da língua portuguesa na $1^{\mathrm{a}}$ classe num contexto sociolinguístico urbano", o português é ensinado como L2 para a maioria das crianças, mas existe um número considerável de crianças para quem o português é língua materna. A metodologia do ensino utilizada em todos os contextos, entretanto, é a mesma, os materiais são os mesmos - atitude que de certa forma provoca desequilíbrio e insucesso escolares, principalmente no ensino público.

No meio rural, onde há predominância das línguas locais (da família bantu), observam-se situações mais drásticas, uma vez que a maioria da população muita raramente fala ou conhece a língua oficial. O que significa que a criança só fala a LP na escola, com o professor. Somente em situação escolar é que os alunos entram em contato com o português. É válido ressaltar sempre que a língua é ao mesmo tempo cultura. Assim, relativamente ao ensino da LP, ele foi realizado sempre num contexto plurilíngue, mas não se chegou a considerar a importância das línguas moçambicanas bantu no processo de ensino e/ou aprendizagem desta língua. Este processo provoca, em alguns alunos, um sentimento de rejeição e de auto exclusão decorrente de um sistema educacional discriminatório, contribuindo para o severo custo do ensino, o que se afigura como uma das causas relevantes da evasão e do insucesso escolar em Moçambique. Olhando bem para este fato, pode-se pensar que o problema está na escola, mas na realidade não é. O problema ancora-se na política de integração nacional, portanto em um fato meramente político.

O currículo do ensino fundamental do Sistema Nacional de Educação moçambicano tem sete classes organizadas em 2 graus. $\mathrm{O} 1^{\circ}$ grau (EP1) compreende cinco classes (da $1^{\mathrm{a}}$ à $5^{\mathrm{a}}$ classes) e o $2^{\circ}$ grau (EP2) corresponde a duas classes $\left(6^{\mathrm{a}}\right.$ e $7^{\text {a }}$ classes). A idade de ingresso para esse ensino é de 6 anos. O Estado não se responsabiliza pelo ensino pré-escolar. Esse ensino é assegurado por instituições privadas. Cada turma do EP1, é ensinada por um professor que leciona todas as disciplinas curriculares, enquanto que, no EP2, cada disciplina é lecionada por um único professor (Ministério da Educação de Moçambique, 2003). Segundo Gonçalves e Diniz apud Timbane (2015), discorrendo sobre "a dinâmica da língua portuguesa no ensino primário", 


\begin{abstract}
quase na totalidade das nossas crianças, quando entram para a escola, não fala Português e, naturalmente, não lê e não escreve. Esta é a situação típica do meio rural, onde prevalece o uso das línguas locais, as línguas bantu, e onde o português é praticamente uma língua "estrangeira": é aprendido e usado na sala de aula, sobretudo através do contato com o professor e com os livros escolares, sendo pouco frequentes as situações de comunicação em que é falado em ambiente natural. No seu dia a dia, em casa com a família e nas brincadeiras com os amigos, as crianças comunicam na sua língua materna (Gonçalves; Diniz apud Timbane 2015, p.3).
\end{abstract}

Neste processo de ensino, há uma tendência de não associar a língua local como meio de escolarização, pelo fato de ter turmas heterogêneas em termos linguísticos e também de se marginalizar as variedades do português. Por outro lado, a valorização da norma-padrão mostra que esse padrão não reflete a realidade do contexto moçambicano, marcado pela heterogeneidade linguística que se encontra vinculada na vida sociocultural. A norma-padrão é neutra, não é língua materna de ninguém, ninguém a domina na totalidade. É uma norma convencional, artificial e difere da norma popular.

\title{
2. O português como instrumento de liquidação do tribalismo/ unidade nacional
}

De acordo com o artigo $10^{\circ}$ da Constituição da República de Moçambique (Moçambique, 2004), "Na República de Moçambique, a língua portuguesa é a língua oficial". Embora a escolha do governo, ao indicar o Português como língua oficial, tenha sido considerada adequada por razões eminentemente políticas, visto que o governo queria acabar com o tribalismo que reinava durante a luta armada e logo após a independência (em 1975), nota-se que a maioria da população moçambicana vive em zonas rurais onde a incidência da pobreza é alta e a falta de serviços básicos como as escolas é uma realidade.

Disso resultam três aspectos a se destacar: (i) primeiro, o fato de a maior parte da população moçambicana não dominar a língua portuguesa, não compreendê-la e não empregá-la em ambiente familiar; (ii) segundo, o fato de Moçambique ser um território onde predomina o uso das LB, que são majoritariamente orais, sendo que a maioria das famílias não são usuárias da escrita alfabética, isto é, as famílias não têm o costume de usar a escrita alfabética em casa, embora se fale LP em alguns casos com frequência. Assim, esta ação representa uma desvantagem para uma criança que vive nesta família, justamente por não saber usar a escrita, já que ela não se depara com os primeiros sinais em casa; e (iii) terceiro, o fato de a escola não promover o contato com a LP a partir da experiência de escolarização em línguas maternas - uma tarefa difícil, já que não existe o ensino massivo nessas línguas (ensino bilíngue), existindo sim um número exíguo de escolas por província, sendo que 
a maioria da população não tem acesso a pré-escolarizacão devido à falta de recursos, uma vez que o Estado não garante.

O ensino de línguas visando à integração das minorias linguística na escola é importante porque possibilita a comunicação plena, a redução do preconceito, a preservação da língua, a elevação da autoestima e impulsiona a criação de dicionários e gramáticas que descrevem a língua. A utilização de uma língua materna minoritária no espaço escolar reforça a continuidade da língua e o ensino durante as primeiras classes (séries) da instrução primária e posterior transição para a língua oficial.

Logicamente, nota-se que a entrada na escola de alunos falantes de diferentes línguas nacionais constitui um enorme desafio, em função dos seguintes motivos: i) devido a não identidade cultural e linguística com a escola e, por conseguinte, com os conteúdos nela ministrados que, na maioria das vezes, entram em conflito com as suas culturas e valores; ii) porque a escola não tem estado preparada para recebê-los, ou seja, não existe um processo de estado que aproxime às pessoas a língua oficial, porque o estado criou a LP como se fez em Portugal, diferente da situação do Brasil que foi uma miscigenação de brancos, índios e negros e suas respectivas línguas e culturas, conforme Soares (2005), "a escola que seria para o povo é, na verdade, contra o povo. Portanto, a escola que existe é antes contra o povo do que para o povo" (Soares, 2005, p.9-10).

Olhando para esta arte da escola, ou seja, ensinar como prática social, Senna (2012) considera que ensinar é levar o outro a viver novos conceitos e incorporá-los aos anteriores. Desta forma, viver a experiência de ensino "é condição imperativa, pois é tomando-a como ato de vida que esta ganha um sentido pragmático, sem o qual nenhum conceito se constitui forte o suficiente para agregar-se aos demais, construídos incidentalmente, por força da intenção de integrar-se à sociedade" (Senna, 2012, p. 54). Concordando com Senna e notando que se ensinar é uma prática social cujo objetivo é levar o outro a viver novas experiências, como se explica, então, que a escola não leve neste caso de Moçambique em conta as experiências de socialização dos alunos? Contudo, olhemos para o que a declaração da UNESCO sobre essa complexidade de ensino multicultural exorta. A Declaração Universal de Direitos Linguísticos (UNESCO, 1996), no seu $2^{\circ}$ artigo, $\mathrm{n}^{\mathrm{o}} 2$ estabelece: $\mathrm{o}$ direito ao ensino da própria língua e da própria cultura; o direito a dispor de serviços culturais; o direito a uma presença equitativa da língua e da cultura do grupo nos meios de comunicação; o direito a serem atendidos na sua língua nos organismos oficiais e nas relações socioeconômicas.

Com efeito, em 1983, foi introduzido o Sistema Nacional de Educação (SNE), que ainda vigora e que já foi revisto de modo a adequá-lo à nova ordem política, 
econômica e social de Moçambique. De acordo com Lopes (2004), consagrou-se a situação anterior como o desenvolvimento das capacidades e qualidades da personagem de uma interação oral e escrita entre os indivíduos; segundo o autor, este sistema permeia a generalização do uso da língua portuguesa, como língua de unidade nacional e foi notória a exclusão da possibilidade de as línguas nacionais desenvolverem essa capacidade.

Apesar dos esforços governamentais, existem, em Moçambique, dificuldades de acesso aos conhecimentos formais. Essa situação é provavelmente oriunda de vários obstáculos, sendo um deles a língua portuguesa, falada e escrita apenas pela minoria da população moçambicana. Nisto, a escola, como local que contribui para a produção dos sentidos, deveria ter a preocupação em contextualizar-se ao meio social do aluno, isto é considerar a sua história de vida, cultura e língua. Parece-nos vaga a pertinência de regular e anularem-se as questões culturais e de língua materna da maioria dos moçambicanos sob pretexto de salvaguardar-se a unidade nacional, pois existem países multilíngues, tal como o caso de Moçambique, que atendem à diversidade, como são os casos de Canada, Suíça, a África do sul e têm unidade nacional melhor que a nossa. Frisa-se que a Declaração Universal dos Direitos Linguísticos (UNESCO, 1996) determina que "todas as comunidades linguísticas têm o direito de organizar e gerir os seus próprios recursos, com vista a assegurarem o uso da sua língua em todas as funções sociais".

$\mathrm{Na}$ tentativa de identificar as possíveis causas deste problema, recorremos à questão basilar da formação do homem, enquanto parte social, isto é, a sua vivência na comunidade. Aqui encontramos escritos de Berger e Luckmann (2005), que nos alertam que qualquer educação que não leve em conta a história, cultura e a língua do aluno está condenada ao fracasso, porque o homem aprende baseando-se na sua experiência primária. Eles enfatizam esse postulado afirmando que

[...] A criança identifica-se com os outros significados por uma multiplicidade de modos emocionais. Qualquer que seja a interiorização só se realiza quando há identificação. A criança absorve os papéis e as atitudes dos outros significativos, isto é, interioriza-os, tornando-os seus. Por meio desta identificação com os outros significativos a criança torna-se capaz de se identificar a si mesma, de adquirir uma identidade subjetivamente coerente e plausível. Em outras palavras, a personalidade é uma entidade reflexa, que retrata as atitudes tomadas pela primeira vez pelos outros significativos com relação ao indivíduo, que se torna o que é pela ação dos outros para ele significativos. Este processo não é unilateral nem mecanicista. Implica uma dialética entre a identificação pelos outros e a auto identificação, entre a identidade objetivamente atribuída e a identidade subjetivamente apropriada (Berger Luckmann, 2005, p.177).

Para Berger e Luckmann (2005, p.39), “[...] a linguagem marca as coordenadas de minha vida na sociedade e enche esta vida de objetos dotados de significação". Estes autores enfatizam que não podemos, de fato, existir na vida cotidiana se não estivermos constantemente em interação e comunicação com os 
outros. Assim, a sociedade, a identidade e a realidade cristalizam subjetivamente o mesmo processo de interiorização. Esta cristalização ocorre juntamente com a interiorização da linguagem, "esta constitui o mais importante conteúdo e credenciamento o mais importante instrumento da socialização" (Berger, Luckmann, 2005, p.179).

Esta realidade sociológica, descrita por Berger e Luckmann (2005), mostra que a socialização primária é aquela que se desenvolve nos primeiros anos de vida, com os seus pais/comunidade. Esta é uma interação familiar feita de forma informal, e de imediato, ela caracteriza e descreve o povo de Moçambique. Neste caso, a socialização da maioria dos alunos moçambicanos não é feita em LP, mas sim nas línguas locais que, por sua vez, estão associadas a um conjunto de práticas sociais e culturais, que segregam os indivíduos, definindo a sua identidade. Portanto, o português só vai aparecer no momento em que o aluno tem expetativa de sair da socialização primária, isto é, quando tem outra perspectiva, como por exemplo, pensar no trabalho, estudos ou formação que o obriguem a mais uma socialização adiante, a dita secundária.

Aqui, nota-se que o custo da alfabetização/letramento pode ser também justificado a partir dessa teoria da socialização, por estar desvinculada da cultura do português no processo de socialização primária dos alunos e, por consequência, torna-se um motivo sério do fracasso escolar no ensino da LP. Nota-se, igualmente, que a escola não caminha em sintonia com a socialização primária, já que não leva em conta o instrumento basilar das relações familiares e escolares que é a língua materna falada na sociedade onde este aluno vive. Para responder a esta questão do custo de alfabetização Bagno (2014), afirma que

muitas e muitas pessoas abandonaram os estudos porque ficam traumatizadas ao entrar na escola e, logo em seus primeiros contatos com o mundo escolar, são alvo de discriminação, de deboche, de piada por causa de seu jeito de falar - discriminação praticada não só pelos colegas, mas também por muitas professoras e muitos professores (Bagno, 2014, p. 57).

No ensino básico moçambicano, como referenciamos no começo do trabalho, há uma grande dificuldade dos alunos progredirem nos estudos, sobretudo nas fases iniciais, devido ao custo da adaptação do português e da escrita alfabética, porque o português não é língua materna da maioria da população. Num estudo sobre o Ensino Primário, em Maputo, Timbane (2014a), afirma que, "a maior parte dos alunos que frequenta o ensino primário são crianças que entram na escola, mas não leem e não escrevem em português, enfatiza dizendo que mesmo aqueles que aprendem o português na família têm enormes dificuldades de se comunicar na sala de aula" (Timbane, 2014a, p.3). 
Nos primeiros anos pós-independência, verificou-se um crescimento acentuado das taxas de admissão no sistema de ensino, mas, nos anos subsequentes, houve um declínio sucessivo que atingiu uma taxa de escolarização de 50,8\%, em 1989. Esta realidade não será, com certeza, alheia à prolongada guerra civil vivida em Moçambique que, além de criar uma situação econômica e política devastadora, destruiu parte da rede escolar existente no país. Por causa deste declínio que se registrou depois dos primeiros quatro anos da independência, em 1979, realizou-se em Maputo o primeiro Seminário Nacional sobre Ensino da LP, e nesse encontro, destacou-se a necessidade de aprofundar o estudo das línguas moçambicanas de modo a poderem desempenhar um papel importante no desenvolvimento científico e cultural do país. Foi neste seminário que nasceu o Núcleo de Estudos de Línguas Moçambicanas (NELIMO) na Universidade Eduardo Mondlane (UEM), que deveria coordenar a pesquisa e a padronização das línguas nacionais.

Nos anos 1990, são financiados vários projetos de universidades e ONGs para o estudo de questões do bilinguismo e das LB faladas em Moçambique. O Instituto Nacional de Desenvolvimento de Educação (INDE) promoveu, em 1991, uma fase experimental de educação bilíngue, com o Projeto de Ensino Bilíngue em Moçambique (PEBIMO), que introduz as LB no ensino básico, em algumas escolas de duas províncias: Tete (usando as línguas Nyanja e português) e Gaza (usando as línguas Changana e Português):

\begin{abstract}
Ante a situação crítica a que se chegou ao domínio linguístico, o INDE, com apoio do governo moçambicano, do PNUD e do Banco Mundial, começou a desenvolver, em fase experimental desde 1993, um currículo bilíngue para crianças não falantes do português à altura do ingresso na escola. O projeto que teve o nome de programa de Educação Bilíngue em Moçambique foi aplicado no nível básico a partir da língua maternal da criança, com passagem posterior para língua portuguesa nas fases seguintes (Lopes, 2004, p. 460).
\end{abstract}

Para Ngunga et al. (2010), nos seus estudos de caso do ensino bilíngue realizados na província de Gaza, afirmam que vários estudos têm vindo a revelar que as crianças são, por um lado, penalizadas por não dominarem a língua que é usada como meio de ensino e, consequentemente, por outro, o sistema educativo tem vindo a registrar grandes perdas de toda a ordem. Para justificar o que sempre se argumenta sobre o ensino nos países colonizados, Benson (2000) diz que todo o currículo foi baseado num modelo do Português Europeu, o que significa que as artes da linguagem são projetadas para falantes nativos de português europeu e que o conteúdo acadêmico é mal adaptado às culturas moçambicanas e aos estilos de vida. Nota-se que este currículo só ajuda a desenvolver as crianças que já têm 
a LP como sua língua materna e continua a perpetuar a exclusão educacional e social para a maioria das crianças oriundas das zonas rurais.

Para Meneses (2013), no seu estudo com professores de ensino bilíngue, esses profissionais se sentiam motivados com as aulas em línguas moçambicanas porque os alunos interagiam, participavam da aula, compreendiam facilmente os conteúdos, mas o único impasse era relativo ao uso da escrita. Por sua vez, fora da sala de aula, os pais ajudavam os alunos na realização de trabalhos escolares em casa, fato que não acontece quando a educação é monolíngue, pois os pais não falam, nem escrevem em português. A constatação do autor mostra claramente que a educação não deve ser feita só na escola, mas sim também na família, porque o objetivo da educação é socializar a criança para conhecer os seus direitos e obrigações de cidadão dentro da comunidade.

\section{O bilinguismo: uma proposta para um sistema de ensino de um país multilíngue}

Por bilinguismo, compreende-se a capacidade de um indivíduo valer-se de dois sistemas linguísticos (Crystal, 1988, p. 39), ou em outras palavras, a competência bilíngue é a soma de vários fatores que, agregados, culminam na proficiência e fluência em duas línguas, sejam elas adquiridas naturalmente ou aprendidas por meio da sistematização. Weinreich (1967) considera que o contato de línguas é visto, por alguns antropólogos, como um aspecto do contato de culturas e a interferência linguística é tida como uma faceta da difusão cultural e da aculturação. Os contatos internos podem incluir a relação entre uma língua dominante ${ }^{2}$, isto é, majoritária, ou línguas dominantes e uma língua minoritária ${ }^{3}$, ou entre línguas minoritárias. Essas situações podem ser encontradas nas fronteiras de países ou dentro de um país; em regiões próximas a países fronteiriços ou em comunidades bilíngues. Ainda segundo Weinreich,

quanto maior for a diferença entre os sistemas, isto é, quanto mais numerosos as formas e padrões mutuamente exclusivos em cada um deles, maior é a dificuldade de sua aprendizagem e a área potencial de interferência, de modo que as diferenças e similaridades entre línguas em contato devem ser exaustivamente descritas para cada domínio como pré-requisito para a análise da interferência (Weinreich, 1967, p. 1-2).

2. Língua dominante ou língua majoritária: refere-se à língua oficial de uma nação e, por ter esse domínio, é geralmente a língua da educação, da administração e da mídia e, consequentemente, da comunidade bilíngue. Não se refere necessariamente à frequência de uso diário ou a número de falantes.

3. Línguas minoritárias ou grupos linguísticos minoritários: são línguas que existem em ambientes hostis a elas. Não são usadas como língua da educação, da mídia e da administração, etc., e, sendo assim, são dominadas por outra ou por outras línguas. Como elas estão limitadas a serem usadas exclusivamente dentro da comunidade que as fala, a ameaça externa a elas deriva desses outros domínios, e o peso da pressão cai de acordo com a importância que esses domínios possuem dentro da comunidade. 
A explicação do autor, nesta citação, descreve claramente e de forma objetiva a situação de bilinguismo em curso em Moçambique, porque as línguas bantu são tipicamente orais e ágrafas e o português é de carácter gráfico e normativo. Portanto, o encontro das duas línguas traz consequências para o falante que quer usá-las. Isto nota-se tanto para os nacionais que pretendem aprender português, como também para os europeus que queiram aprender as línguas bantu, devido a estas diferenças em termos de estruturas e falta de similaridades.

A partir de outra visão, Senna (1991) afirma que o bilinguismo não é apenas o domínio de outra língua, mas sim é um processo que acontece na cabeça de um sujeito quando incorpora dois sistemas linguísticos ao mesmo tempo num espaço cultural. Nesses termos, isso só vai acontecer quando o sujeito aceitar que as duas línguas são importantes e quando começar a misturar uma língua com a outra: aí haverá bilinguismo. Enquanto o sujeito não misturar uma com a outra língua, significa que há uma que prevalece sobre a outra, sendo daí mais importante.

Em outro estudo realizado por Ngunga et al. (2010), citando informação do INDE (2001), os autores destacam que, com a reforma do ensino básico, introduz-se a língua materna como disciplina (da $1^{\mathrm{a}}$ a $5^{\mathrm{a}}$ classe) e como meio de ensino (da $1^{\mathrm{a}}$ a $3^{\mathrm{a}}$ classe). O Plano Curricular de Ensino Básico (PCEB, 2003), reformulado a partir do antigo, introduzido em 1983, elaborado pelo INDE, apresenta o uso das línguas moçambicanas no ensino como uma inovação na reforma Curricular. Ainda de acordo com Ngunga et al (2010), a sua implementação viria a ser iniciada no ano letivo de 2003 e, numa primeira fase, a educação bilíngue, deveria ter lugar em regiões rurais linguisticamente homogêneas como forma de permitir que cada moçambicano aprenda os primeiros rudimentos de leitura/escrita e aritmética na sua LB materna. As crianças moçambicanas têm normalmente duas línguas ao mesmo tempo e em formação com uma relevância comunicativa esta situação traz sempre problemas para aquelas crianças que não tiveram essa situação bilíngue na socialização primária. Há, contudo, fatores de ordem sociocultural que interferem no predomínio de uma língua sobre outra. Para o caso de Moçambique, existem duas línguas a LB e a LP que coabitam no mesmo espaço e tempo, em que o português sai a ganhar, porque é a língua de ascensão social na vida. Assim, a sociedade moçambicana tem o poder de decidir quem sai e quem fica na ascensão através desta língua. Quando isto se verifica, entra em cena outro valor chamado diglossia.

É impossível pensar a aprendizagem de uma segunda língua, em contextos formais ou informais, sem a ocorrência de transferências da língua materna para a língua segunda. Independente do contexto em que essa aquisição irá se inserir, existirá um processo gradual caracterizado pela dinamicidade da língua. No 
processo de aprendizagem da língua estrangeira, os aprendizes baseiam-se no conhecimento que têm de sua língua materna para compreender como a língua estrangeira é estruturada. Desta forma, nesse processo de associações com a língua materna, geralmente ocorrem transferências. É nessa mistura de dois sistemas que ocorre o fenômeno do bilinguismo, que posteriormente a sociedade irá traduzir em diglossia. Ferguson apud Wardhaugh (1992) sumarizou diglossia como:

um fenômeno social, um bilinguismo estendido à comunidade linguística. Apenas duas variedades linguísticas estão nele envolvidas, há uma variante da língua muito divergente, altamente codificada (muitas vezes, bastante complexo gramaticalmente) sobrepondo-se à variedade. É o veículo de um grande e respectivo corpo de literatura escrita (Ferguson Apud Wardhaugh, 1992, p. 89).

O fato é que, em Moçambique, existem fatores que demostram esta situação. O público que detém o poder sobre uma língua usa esse sistema para dominar ou excluir os outros. Neste caso, temos uma diglossia, embora não institucionalizada, tal como o caso da Índia com o hindu e inglês, a África islamizada com o árabe clássico (para o clero e aristocracias), e o árabe fluente (maioria da população), isto é: não só entre a LP e as LB ocorre esse fenômeno de dominação, mas também entre as línguas nacionais (ndau e sena, changana e tsuwa, makhwua e makonde) que coabitam num mesmo espaço geográfico, há sempre tendências por detrás desta coabitação de tentativas de valorização ou sobreposição de uma em detrimento da outra, as quais sempre terminam em conflito étnico. Nesse sentido, a partir de casos de diglossia perpetuam-se casos de exclusão, destacando o núcleo de poder. Nota-se claramente que há uma barreira da atual sociedade na construção de identidade nacional através da LP, porque existem certos grupos locais que têm poder para instituir o idioma, pondo em cheque a língua do outro (isto fora do alcance escolar). Quando temos uma sociedade com tendência à diglossia, mesmo tirando-se o português e colocando-se uma língua local, a situação vai persistir.

Neste momento, como referimos no começo do trabalho, a educação bilíngue está numa fase experimental e, no entanto, "há uma imposição implícita nos programas monolíngues em português quando elas são a única opção" (Patel; Cavalcanti, 2013). Segundo Timbane (2015), especialistas e educadores estão cientes das consequências de uma educação monolíngue tal como é sugerido pela política linguística do país. O uso do português como língua de ensino limita seriamente a comunicação entre professores, alunos e outros membros da comunidade. Para crianças e jovens, implica uma maior dificuldade de compreensão do processo de ensino/aprendizagem. Eles não podem compreender nem interagir verbalmente com os professores que não falam sua língua, e estes não podem dar conselhos 
que são especialmente valorizados pelos pais das crianças. Para os pais monolíngues, significa que ficam impedidos de dialogar com os professores de sua comunidade. Os adultos se veem confrontados com uma perda de controle sobre a educação de seus filhos pelo fato de não poderem "estabelecer práticas" com os docentes, acabando por se sentirem marginalizados dos assuntos da escola.

O especialista Lopes, no seu estudo de 2004, relativo à introdução do ensino bilíngue em Moçambique, coloca questionamentos sobre a fase do ensino primário no qual melhor seria aplicável o letramento em línguas locais moçambicanas. Considera que se tal estratégia for implementada no começo do ensino primário, esse seria o caminho mais lógico; porém, chama atenção às grandes dificuldades das crianças moçambicanas em aprender a ler e escrever em português, uma língua estranha para elas. Outra possibilidade levantada seria a de começar-se no fim do ensino primário. Sobre ela, Lopes (2004) considera que "dever-se-ia definir como objetivo que nenhuma criança deixaria a escola primária sem ter igualmente aprendido a ler ou a escrever na sua língua materna" (Lopes, 2004, p. 473). Segundo Lopes, na prática, a criança teria acesso à aprendizagem da leitura e da escrita nas línguas maternas a partir da $4^{\mathrm{a}}$ ou $5^{\mathrm{a}}$ classes do ensino primário.

Outro questionamento acerca deste sistema bilíngue adotado pelo estado refere-se à formação e posterior afetação ${ }^{4}$ do professor que não obedece um critério claro em sua prática docente. Segundo Timbane (2015, p.7), o processo de afetação não olha para a região de origem nem a(s) língua(s) falada(s) pelo novo professor. O que acontece, muitas vezes, é que os professores são colocados em regiões onde a língua da comunidade não coincide com a sua própria língua, todavia, ele tem que dar aulas porque é lá onde foi afeto e é o lugar da garantia do seu sustento. Corroborando com o autor, isso aumentaria o problema. Mas a liberdade do professor de trabalhar na comunidade onde conhece a língua local seria uma prioridade do Ministério da Educação, pois faria com que os professores que conhecem a mesma língua que o aluno possa ensinar e fazer progredir a educação bilíngue. Um dos objetivos do PEBIMO, como afirma Lopes (2001), é a democratização e o acesso de todos ao ensino, reduzindo o insucesso escolar e servindo de base de todo o processo de transformação curricular, com vista ao alcance dos objetivos da educação para todos. Segundo Lopes afirma

a política linguística de Moçambique deveria se orientar para a criação de condições conducentes a
um uso mais amplo do português e também a possiblidade de uso das línguas nacionais em contextos
institucionais, como a educação formal, tribunais estatais, aparato administrativo ou meio de comuni-
cação de massa; em suma, sempre que se sinta que o português é uma barreira linguística. As línguas

4. É neste caso a colocação ou alocação de um professor numa dada escola após a sua formação nos Institutos de Magistério Primário. 
e o acesso de todos ao ensino, reduzindo o insucesso escolar e servindo de base de todo o processo de transformação curricular, com vista o alcance dos objetivos da educação para todos (Lopes, 2001, p.8).

Todas as mais-valias retiradas desta nova política, que contempla tanto a introdução das línguas bantu no ensino, como a sua proteção, desenvolvimento mais equitativo, aproximação da escola à sociedade, a gestão da identidade, entre outras, acabam no seu conjunto por viabilizar o ensino bilíngue. Apesar desses esforços, Lopes (2001) considera que um dos principais fatores responsáveis pela falta de sucesso escolar (principalmente no ensino fundamental) em Moçambique "é a falta de um bilinguismo sistemático que utilize um letramento completo até um nível suficientemente elevado na língua materna como base de um letramento numa segunda língua" (Lopes, 1999, p.85). Os estudos de Lopes mostraram como uma análise rigorosa de todas as experiências poderá ilustrar a importância decisiva dessa base, ainda que só isso não seja suficiente. Lopes acrescenta ainda que

esta realidade não é reconhecida, porque os especialistas preferem a utilização de línguas francas e segundas para evitar a multiplicação de inversões considerando o monolinguismo como um fator positivo para a aglutinação das diferentes etnias de um Estado numa Nação, e para a modernização considerada como uma proposta de desenvolvimento econômico. Estes especialistas, que dominam todas as grandes organizações internacionais, reproduzem o método utilizado pelas classes dirigentes dos Estados-nacionais dos países industrializados, que, historicamente alcançaram a designada "civilização " pela opressão e eliminação de línguas, culturas e, às vezes povos. Na realidade este método, além de ser opressor revela-se na atualidade pouco eficaz (Lopes, 1999, p.85, grifos do autor).

As pesquisas mostram que, deste modo, estas populações não se unem política e culturalmente, não se desenvolvem economicamente, nem são escolarizadas com êxito; continuam marginalizadas, provocando um conjunto de problemas que, em última análise, procura-se solucionar com intervenções militares efetivas por forças nacionais e internacionais. Quando um povo tem segurança, um bom nível de vida, liberdade e identidade, em vez de violência, miséria, repressão e alienação, pode constituir-se como Nação e ter uma identidade nacional, independentemente do fato de o Estado ser mono ou multilíngue, mono ou multicultural.

\section{As práticas docentes e o desafio do bilinguismo: metodologia e análises}

Este trabalho possui uma metodologia qualitativa, já que as resposta sobre este estudo encontramos nas diversas obras lidas. Ao consultarmos estas obras, analisamos profundamente como o ensino em contexto multilíngue é complexo, bem como olhamos para as políticas públicas de educação determinadas pelo Governo e fizemos um levantamento de problemas, apresentando algumas sugestões 
como possíveis soluções. Como se pode observar, o privilégio atribuído à LP é resultado da política e do planejamento político vigente, iniciado pelo sistema colonial e apoiado pelo primeiro Governo de Moçambique em 1975 e não por improbabilidade linguística das LB. As LB têm uma estrutura linguística completa que permite aos seus usuários comunicar sem restrições, tal como o português, inglês ou outras.

Segundo Timbane (2015), "todos os seres humanos, independentemente de sua escolaridade ou de sua condição social, a menos que tenham graves problemas psíquicos ou neurológicos, falam" a sua língua materna. A maior parte dos moçambicanos possui pelo menos uma LB como língua materna e o número atinge $89 \%$, segundo dados do Instituto Nacional de Estatística (2009). Isto demostra que cada cidadão é portador de uma cultura que deve ser preservada, já que com a morte de uma língua, parte da história da população moçambicana também desaparece. O mosaico linguístico de Moçambique coloca ao ensino básico o desafio de implementação de práticas docentes que respeitem essa diversidade. Em um estudo relativo ao propósito e ao valor da introdução do ensino bilíngue em Moçambique, Chimbutane (2009) concluiu que o principal propósito do seu uso é facilitar a aprendizagem dos alunos, tendo identificado valores pedagógicos, socioculturais e socioeconômicos associados ao bilinguismo. Chimbutane concluiu também que os benefícios nas comunidades locais centram-se mais em aspectos de natureza sociocultural do ensino bilíngue, visto como alavanca o desenvolvimento e a valorização de aspectos socioculturais.

Por último, Chimbutane (2009) considera que a introdução do ensino bilíngue possibilitou que alunos e professores começassem a considerar o potencial e o valor das línguas locais nos contextos formais. A conclusão do estudo de Chimbutane (2009) indica que o ensino bilíngue desempenha um importante papel transformador social e cultural, possuindo um enorme potencial a ser explorado, mas o Estado precisa disponibilizar professores e material didático com livros e dicionários nestas línguas. Num outro estudo, Patel e Cavalcanti (2013) apud Timbane (2015), apoiam uma educação bilíngue de enriquecimento (aditiva) e não uma educação bilíngue de transição (subtrativa). Nesse caso, trata-se de uma educação bilíngue que valoriza a comunicação, a inteligibilidade mútua, e não a idealização da proficiência. Este ensino permite que a criança não fique inibida, com medo, acanhada, confusa, por não conseguir se comunicar corretamente na vida estudantil, porque pode inibir a sua criatividade linguística e cognitiva. Através deste tipo de educação, é possível promover uma formação integral do aluno, como sujeito pensador, observador, que estuda e realize sua história, que se constitui de experiências e saberes, independente das suas capacidades serem 
mais ou menos desenvolvidas, pois as crianças mostram-nos a todo o momento como aprendem, quando aprendem e com quem aprendem; e, na maioria das vezes, não damos a devida importância a esses fatos fundamentais do cotidiano da sala de aula.

\section{A tripartida relação entre língua $x$ cultura $x$ ensino}

Olhando para as tradições africanas dos povos bantu, localizados geograficamente na região da África Ocidental, Central e Austral, observam-se claramente nos ritos tradicionais como estes três aspectos a língua, a cultura, e a educação informal são passados para as crianças. Especificamente em Moçambique, os ritos de iniciação são uma escola, na qual estes três conceitos aqui apresentados são discutidos e ensinados às crianças, uma vez que elas precisarão de uma língua para se comunicar, precisarão conhecer as regras de ser e de estar na sociedade (cultura) e esses processos são realizados pelos anciões (madodas), madrinhas e outros intervenientes como líderes comunitários. Entendamos a 'cultura' como o conjunto de padrões de comportamento, de conhecimento, de crença, da arte, da moral, da lei, dos costumes e de todos os outros hábitos e capacidades adquiridas pelo homem como membro da sociedade (Timbane, 2014a, p.46).

Saussure (2006, p.17) definiu a língua como "um produto social da faculdade de linguagem e um conjunto de convenções necessárias, adotadas pelo corpo social para permitir o exercício dessa faculdade nos indivíduos." Coseriu (1959, p.28), por sua vez, trata a língua como um "sistema expressivo que dentro duma comunidade humana serve de meio de expressão.” Entendamos, portanto, a língua como o conjunto de signos, de sinais que um grupo de indivíduos pertencentes a uma comunidade padroniza intencionalmente para servir de instrumento de comunicação que expressa ideias, sentimentos, constatações e pensamentos, incluindo a transmissão da cultura.

A língua é abstrata e, assim, ela se manifesta através da fala/escrita ou de sinais. A fala é individual e é por essa razão que linguistas forenses consideram a fala como uma impressão digital, pois ninguém fala/escreve/ sinaliza igual ao outro. Cada um tem seu timbre de voz, tem escolhas lexicais próprias, produz pausas e entonações próprias o que significa que a fala possui características individuais que os sociolinguistas designam por idioleto. As definições de língua dadas por Coseriu (1959) e por Saussure (2006) encontram sentido aqui, pois a língua está na mente dos indivíduos e na cultura em que estão inseridos.

Um exemplo da ligação entre língua e cultura está mais visível no léxico. A junção do léxico e da cultura designamos por lexicultura. Esta lexicultura pode ser geral ou específica. Para Timbane (2014b, p.47), a lexicultura geral 
é "aquele conjunto de itens lexicais que são identificados por toda comunidade linguística, neste caso, a comunidade lusófona." Inclui-se aqui unidades lexicais comuns na lusofonia. Por outro lado, a lexicultura específica refere-se ao "conjunto de itens lexicais que caracterizam uma variedade ou variante específica, ou seja, pertence a um grupo restrito. Pertencem a este grupo, por exemplo, os angolanismos, os brasileirismos, os moçambicanismos etc..." (Timbane, 2014b, p.47). As palavras ônibus, capivara, tuiuiú, aipim são unidades lexicais de fácil compreensão entre os falantes da variedade do português do Brasil, portanto, brasileirismos. Por seu turno,

uma unidade lexical mais recorrente entre os moçambicanos é a palavra txopela, estrangeirismo proveniente da língua xichangana. Vem do verbo ku txopela (rabeirar). Assim, no contexto moçambicano, txopela designa um tipo de moto-taxi coberto para proteger o passageiro do frio e da chuva e que muitas vezes está equipado com aparelho de som (Timbane, 2014b, p51).

Há ainda preconceito com relação às LB e os moçambicanismos. Em função disso, advogamos no sentido da imediata criação de dicionários de moçambicanismos, por forma a atender as necessidades comunicativas dos alunos. A comunicação escrita é a menos usada, principalmente em comunidades onde predomina a tradição oral. A escrita é uma forma de comunicação que é possível graças à intervenção da educação formal, quer dizer, para o seu domínio é necessário que o indivíduo seja alfabetizado. Por isso que ocorre de forma planejada, com possibilidades de correção, como livre consulta e reformulação textual antes que seja divulgada.

A língua, a cultura e o ensino no espaço escolar, juntos constituem um passo importante para uma educação de qualidade que respeita os valores de um grupo social. Hoje, já não se senta "à volta da fogueira" (como antigamente), mas sim "à volta da televisão e da internet". Os ensinamentos das novas tecnologias levam os jovens para caminhos sinuosos quando não são acompanhados pelos pais ou tutores (professores). Os multiletramentos são uma prova de como se pode aproveitar as tecnologias em prol do ensino. Concordamos com Burgeile e Lazaro quando afirmam que é preciso "implementar medidas, programas em parceria, sempre considerando que cada cultura possui valores próprios que nem sempre podem ser mesclados multiculturalmente, isto é, de maneira monovalente, mas sim tratados interculturalmente...”(Burgeile, Lazaro, 2009, p.64).

\section{Considerações finais}

Moçambique, igual a muitas nações no Mundo, e em particular em África, tem um processo histórico caracterizado pela presença de povos provenientes 
de diversas regiões, movidos por vários interesses: religião, comércio, prática de agricultura, pastorícia, etc. A geografia linguística de Moçambique é formada por estruturas que desenvolveram suas identidades linguísticas e étnicas por períodos muito longos. Assim, tal como no período colonial, o uso das diversas línguas locais era banido por lei, sobretudo em função do valor que era a elas atribuído pelo poder instituído. No período que se seguiu à independência, não foi criado um quadro jurídico que valorizasse seu uso, pesquisa, desenvolvimento e preservação. Até hoje, essa valorização ainda é diminuta porque, em nível oficial, só foram introduzidas na escola, mas nas Instituições públicas, não. Isto mostra claramente que as LB não são línguas de ascensão social, por isso, a sua implementação nas zonas urbanas é impossível porque ninguém quer ver seu filho a atrasar na corrida à vida acadêmica e profissional.

$\mathrm{O}$ resultado disso, no processo de ensino-aprendizagem destas línguas, é negativo, visto que os alunos não têm desenvolvido as necessárias competências nestas línguas que os identificam. Esta situação vai perpetuando a dita exclusão linguística na sociedade, aliado a isso a morte de algumas línguas ou de suas variantes e, com isso, desaparece uma parte da história do grupo étnico. Nota-se que a introdução do ensino das línguas nacionais no sistema de ensino não é tão eficaz, já que estas foram introduzidas como uma ponte para que os alunos se adaptem ao Português com uma referida tranquilidade, mas não como um ensino sistematizado em que o aluno posteriormente poderá usá-las nos setores públicos, como na Saúde, Comércio, Justiça etc. Assim, novos modelos de práticas docentes precisam ser adotados para a solução do problema do fracasso escolar, sobretudo se forem implementadas com estrito respeito às necessidades de aprendizagem de alunos falantes de diversas línguas locais que caracterizam Moçambique.

Os sistemas de educação vigentes na maioria dos países africanos foram criados intencional e especificamente para reforçar a ideologia colonial de dominação, segundo a qual, os africanos precisam civilizar-se, pois são selvagens e sem cultura. É desta forma preconceituosa que o sistema colonial difundia e incutia menosprezo na mente dos africanos. Até hoje, isso se observa quando o ensino recusa a cultura do aluno considerando-a atrasada e pobre valorizando assim culturas e línguas alheias. É triste quando a Constituição da República de Moçambique, no seu artigo 9, prefere "valorizar" as línguas nacionais sem lhes dar o valor da oficialidade que é mais prestigiosa. Existe uma hierarquia entre uma língua nacional e uma língua oficial. É lógico que a língua oficial terá mais privilégios e poderes (Severo, 2013) do que uma língua nacional. Concluindo, a independência linguística ainda não foi proclamada. A educação ainda não responde os interesses da comunidade. A comunidade ficaria feliz se a escola valorizasse a cultura 
e as línguas, pois as crianças e jovens são formadas para apoiar a comunidade. Proibir práticas culturais e lassifica-las como pobres ou ultrapassadas é mutilar a identidade do sujeito, tornando-o assim aculturado.

O objetivo deste capítulo foi de discutir alguns aspectos relativos ao ensino básico em Moçambique, particularmente no que se refere às experiências de práticas de leitura e escrita escolar, bem como abordar e discutir as possíveis causas que levam o aluno ao fracasso escolar, refletindo e analisando as justificativas apontadas por alguns teóricos, tendo como principal enfoque as classes de alfabetização compostas por alunos provenientes de famílias pertencentes às classes multiculturais que caracterizam a sociedade moçambicana. $\mathrm{O}$ incentivo a estas línguas, através da sua oficialização nas instituições públicas, possibilitaria provavelmente o seu desenvolvimento e valorização no meio social, além de promover o desenvolvimento abrangente dos interlocutores sociais. Portanto, trata-se também de promover o resgate das línguas nacionais que estão caindo no esquecimento. A literatura nessas línguas deve ser criada e divulgada, a alfabetização em LB deve ser uma prática social obrigatória para os sujeitos dessas línguas, para que ninguém possa sair do Ensino Básico sem pelo menos falar e escrever numa destas línguas. Nesse caso, até a questão da estranheza com as LB iria diminuir e ajudaria os alunos a produzir textos práticos que fazem sentido na vida social. Esta seria também uma maneira de defender os Direitos linguísticos das minorias.

\section{Referências}

Bagno, Marcos. Língua, linguagem, linguística: pondo os pontos nos ii. São Paulo, Parabola, 2014.

Benson, Carolyn J. The primary bilingual education experiment in Mozambique, 1993 to 1997. International Journal of Bilingual Education and Bilingualism, v.3, n³, p.149-166, 2000.

Berger, Peter; Luckmann, Thomas. A construção social da realidade. Petrópolis: Vozes 2005.

Burgeile, Odete.; Lazaro, Pancho Richard P. Formulação de uma agenda de educação multicultural em políticas públicas. In: Burgeile, Odete.; Rocha, Júlio César B. (Org.). Estudos em linguística aplicada: multiculturalismo e ensino-aprendizagem de línguas. São Carlos: Pedro e João Editores, 2009, p.53-66.

Chimbutane, Fernand S. The purpose and value of bilingual education: a critical, linguistic ethnographic study of two rural primary schools in Mozambique. 2009. 443f. Tese de Doutorado (Educação). Instituto de Educação, Universidade de Birmingham, 2009.

Coseriu, Eugene. Teoria da linguagem e linguística geral: cinco estudos. Rio de Janeiro: Presença, 1959.

Crystal, David. Dicionário de linguística e fonética. Trad. Maria Carmelita P. Dias. Rio de Janeiro: Jorge Zahar, 1988. 
Instituto Nacional de Desenvolvimento da Educação. Programa do ensino básico. Maputo: INDE, 2001.

Instituto Nacional de Estatística. Recenseamento geral da população e habitação-2007. Maputo: INE, 2009.

Ki-Zerbo, Joseph. Para quando África: Entrevista com René Holenstein. Trad. Carlos Aboim de Brito. Rio de Janeiro: Palllas, 2006.

Lopes, José de Sousa Miguel. Cultura acústica e letramento em Moçambique: em busca de fundamentos para uma educação intercultural. Educação e pesquisa. São Paulo, v. 25, n. 1, p. 6787, jan./jun. 1999.

Lopes, José de Sousa Miguel. Escola e política linguística em Moçambique: a cidadania ameaçada. Teias: Rio de Janeiro, ano 2, n.3, p.1-10. Jan./jun.2001.

Lopes, José de Sousa Miguel. Cultura acústica e letramento em Moçambique: em busca de fundamentos antropológicos para uma educação intercultural. São Paulo: EDUC, 2004.

Malik, Khalid. Índice de desenvolvimento humano. New York: PNUD, 2014.

Meneses, Leonardo J. J. M. O ensino bilíngue em Moçambique: entre a casa e a escola. Salvador. 2013. 465 p. Tese de Doutorado. Universidade da Bahia, Brasília, 2013.

Moçambique. Constituição da República de Moçambique. Maputo: Imprensa Nacional, 2004.

Ngunga, Armindo. Et al. Educação bilíngue na província de Gaza: uma avaliação de um modelo de ensino. Maputo: CEA/UEM, 2010.

Patel, Salmina A.; Cavalcanti, M. O caso do português em Moçambique: unidade nacional com base em educação bilíngue e intercompreensão. 2013.

Saussure, Ferdinand. Curso de linguística geral. São Paulo: Cultrix, 2006.

Senna, Luiz Antônio Gomes. Lingua materna e língua culta: pequeno manual de linguística geral e aplicada. Rio de Janeiro: LAG Senna, 1991.

Senna, Luiz Antônio Gomes. Letramento, princípios e processos. 1.ed. Curitiba: PIS, 2012.

Severo, Cristine G. Política(s) linguística(s) e questões de poder. Alfa. São Paulo, v.57, n.2, p.451-473, 2013.

Soares, Magda. Letramento: um tema em três gêneros. Belo Horizonte: Ed. Autêntica. 2005.

Timbane, Alexandre A. A problemática do ensino da língua portuguesa na $1^{a}$ classe num contexto sociolinguístico urbano: o caso da cidade de Maputo. 2009. 121f. Maputo, Moçambique. Dissertação de Mestrado. Universidade Eduardo Mondlane, 2009.

Timbane, Alexandre A. O ensino da língua portuguesa em Moçambique e a problemática da formação de professores primários. Difere: Artifícios, v. 4, n.7, jun. 2014a.

Timbane, Alexandre A. A lexicultura no português de Moçambique. Linguagem: estudos e pesquisas. Catalão, vol. 18, n. 2, p. 43-59, jul./dez. 2014 b.

Timbane, Alexandre A. A complexidade do ensino em contexto multilíngue em Moçambique: políticas problemas e soluções. Calidoscópio. V.3, n. 1, p. 92-103, jan/abr 2015.

UNESCO. Declaração universal dos direitos linguísticos. Barcelona : UNESCO, 1996. 
120 | RILP - Revista Internacional em Língua Portuguesa - nº 32 - 2017

Wardhaugh, R. An introduction to sociolinguistics. $2^{\text {a }}$ ed. Oxford: Blackwell, 1992.

Weinreich, Uriel. Languages in contact. 5.ed. The Hague: Mouton, 1967. 